\title{
Acute Epiploic Appendagitis of the Vermiform Appendix: Typical Computed Tomographic Image with Pathologic Correlation
}

\author{
Jung Wook Seo \\ Department of Radiology, Ilsan Paik Hospital, Inje University College of Medicine, Goyang-Si, Korea \\ Email: seojwrad@paik.ac.kr
}

How to cite this paper: Seo, J.W. (2017) Acute Epiploic Appendagitis of the Vermiform Appendix: Typical Computed Tomographic Image with Pathologic Correlation. Advances in Computed Tomography, 6, 21-27.

https://doi.org/10.4236/act.2017.64004

Received: September 22, 2017

Accepted: November 5, 2017

Published: November 8, 2017

Copyright $\odot 2017$ by author and Scientific Research Publishing Inc. This work is licensed under the Creative Commons Attribution International License (CC BY 4.0).

http://creativecommons.org/licenses/by/4.0/

\begin{abstract}
Epiploic appendages can become ischemic and infarcted, which can present acute abdominal pain that mimics other diseases, such as diverticulitis or appendicitis. Particularly, inflammation of an epiploic appendage attached to the vermiform appendix is a very rare cause of acute abdominal pain, and it is difficult to diagnose this condition preoperatively. We present a case of epiploic appendagitis of the vermiform appendix that was identified with a typical radiologic image and was pathologically confirmed. In addition, we review the literature of similar cases and analyze the clinical and radiologic features of EA of the vermiform appendix.
\end{abstract}

\section{Keywords}

Acute Abdomen, Appendix Epiploica, Epiploica Appendagitis, Vermiform Appendix, Computed Tomography

\section{Introduction}

Epiploic appendagitis (EA) is an uncommon self-limited condition that is caused by inflammation and ischemia related to torsion, or venous thrombosis, of the epiploic appendages [1]. In particular, inflammation or torsion of the epiploic appendages in the vermiform appendix is an extremely rare cause of acute abdominal pain and it is difficult to diagnose this condition preoperatively [2]. To our knowledge, fewer than 10 cases have been reported in the English literature since Hambury first reported the disease in 1952 [3]. Although EA is rarely diagnosed preoperatively; knowledge of this condition is important as it may mimic other forms of acute abdominal pain that require surgery, when it can be 
treated conservatively with pain management. Therefore, clinicians and radiologists should be familiar with the characteristic radiologic features of EA to prevent unnecessary surgery.

We report the first case of EA of the vermiform appendix identified with a typical computed tomography image and pathologic correlation, and review 5 additional cases reported in the literature.

\section{Case Presentation}

A 32-year-old man visited the emergency department complaining of acute right lower abdominal pain that had started 6 hours previously. He had no underlying disease and no other associated symptoms, such as nausea, vomiting, or diarrhea. His vital signs were immediately assessed: body temperature was $36.6^{\circ} \mathrm{C}$, pulse rate was 71 beats per minute, blood pressure was 145/75 $\mathrm{mmHg}$, and respiratory rate was 20 breaths per minute. Physical examination revealed marked tenderness in the right lower quadrant. Clinical laboratory results indicated leu-

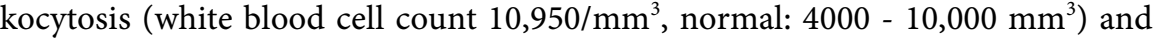
elevated erythrocyte sedimentation rate of $14 \mathrm{~mm} / \mathrm{h}$ (normal $<12 \mathrm{~mm} / \mathrm{h}$ ). Although an intravenous painkiller and fluid therapy were administered, his right lower quadrant pain worsened.

Abdominal radiography showed nonspecific distribution of bowel gas without any sign of bowel obstruction. Abdominopelvic computed tomography (APCT) was performed using a 64-channel multi-detector CT system (Aquilion; Toshiba, Tokyo, Japan), and the contrast medium used was Iohexol (IO-Brix; Taejoon Pharm, Seoul, Korea). APCT showed a $1.5-\mathrm{cm}$ oval, fatty lesion with localized fat stranding and an engorged central vessel closely abutted to the tip of the vermiform appendix. The proximal portion of the vermiform appendix showed no definite evidence of inflammatory change and had a relatively normal diameter (Figure 1(a), Figure 1(b)). However, the surgeon considered the patient to have acute appendicitis and decided to perform an immediate surgical intervention before the CT results were provided.

During surgery, the vermiform appendix was found to be normal in appearance, with mild inflammatory changes in the tip portion and inflamed epiploic appendages attached to the tip of the vermiform appendix. Therefore, a laparoscopic appendectomy was performed. Pathology showed lobulated fibrofatty tissue attached to tip of appendix, with fibrin components, acute inflammation, and a tubular structure suspected to be an engorged vessel, and showed reactive hyperemia in tip of appendix (Figure 1(c)).

\section{Discussion}

Inflammation or torsion of epiploic appendages are rare causes of acute abdominal pain. EA is a self-limited condition, most often affecting middle-aged men, which is caused by inflammatory and ischemic changes related to torsion or venous thrombosis of the epiploic appendages. Because epiploic appendages 
are larger and more numerous in the descending and sigmoid colon, EA typically manifests as left lower quadrant pain, mimicking acute diverticulitis. Less frequently, it can also involve the cecum and ascending colon, and this may clinically mimics appendicitis. Epiploic appendages can also exist in the vermiform appendix and are usually smaller than those on the colon. However,

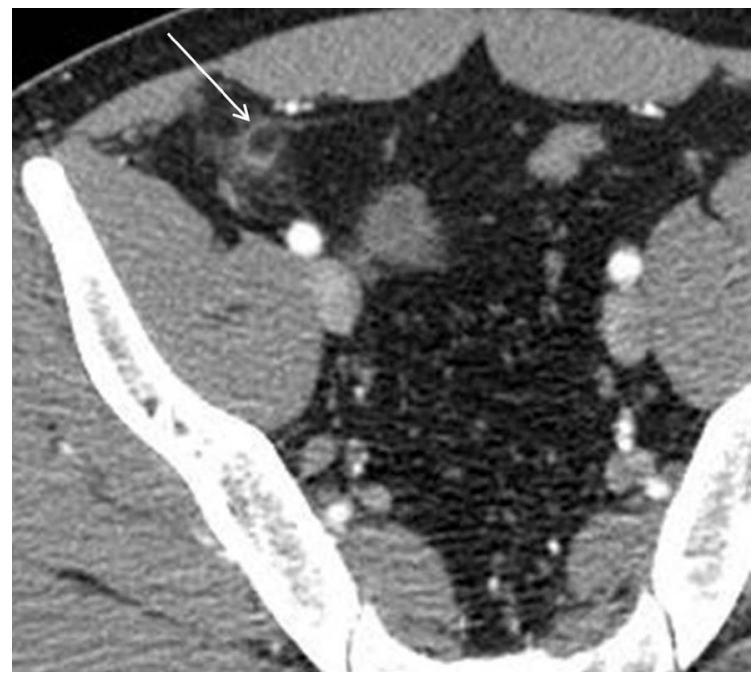

(a)

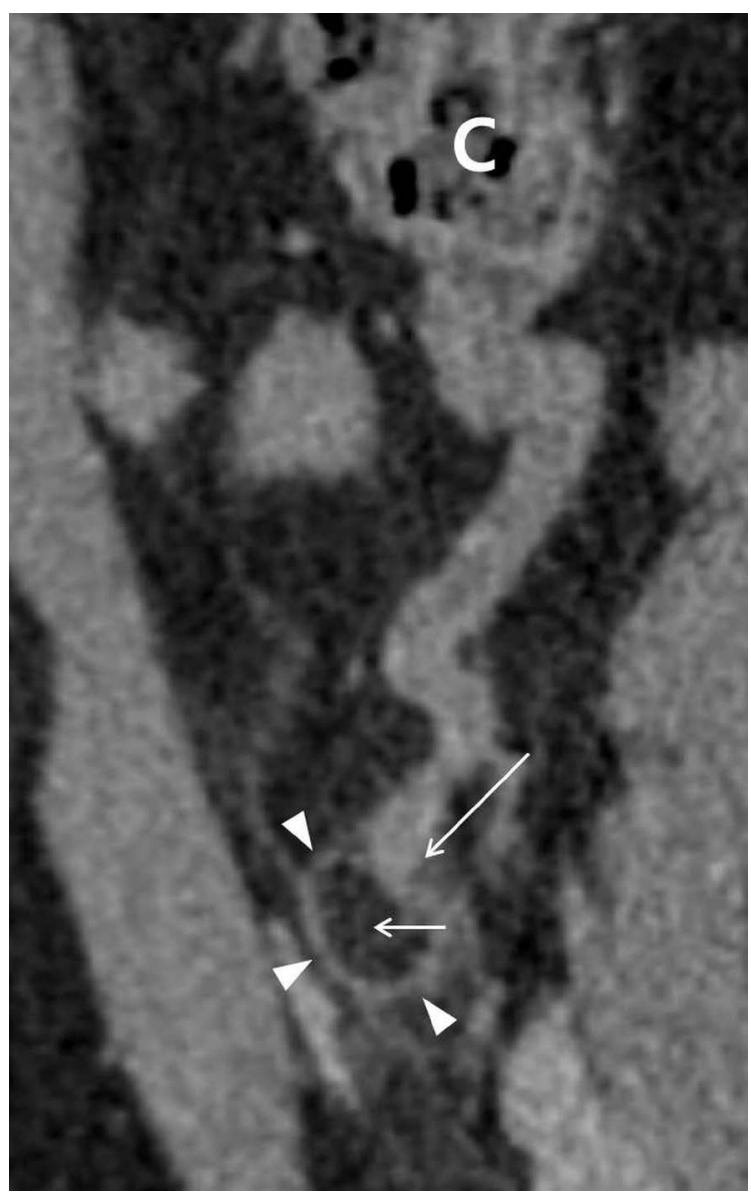

(b) 


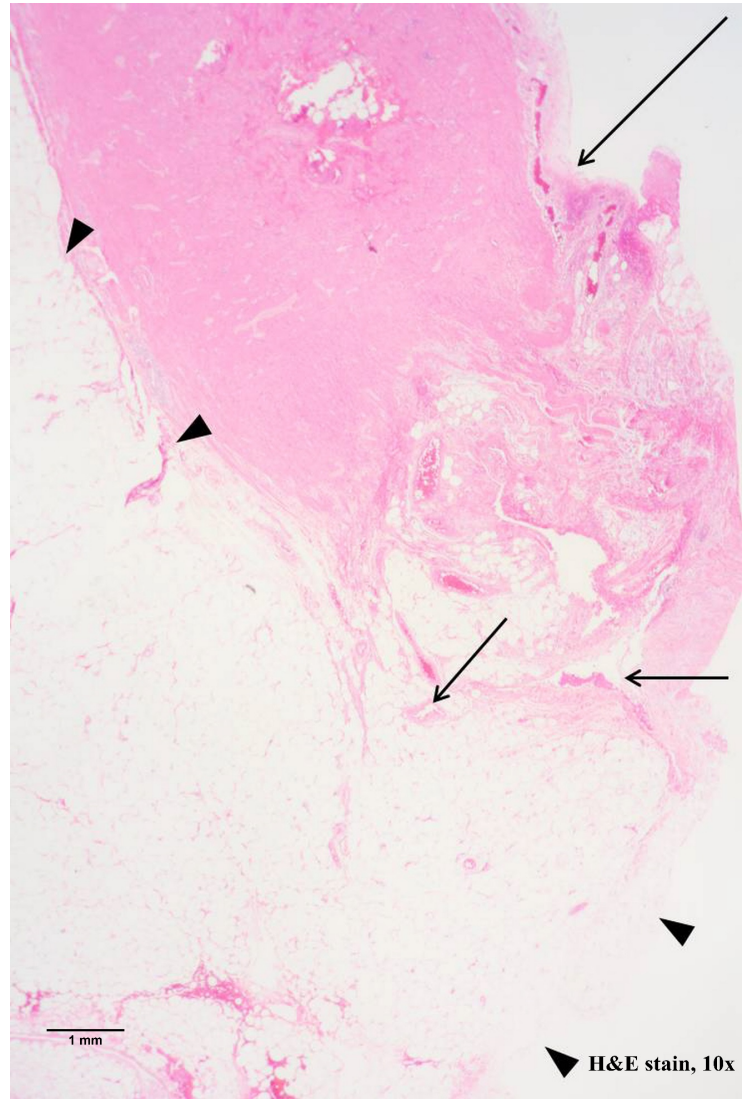

(c)

Figure 1. A 32-year-old man with EAA. (a) Axial scan of contrast-enhanced abdominopelvic computed tomography (CT) shows a fatty oval lesion (arrow) with hyperattenuating rim and fat stranding in the right lower quadrant, around the tip of the vermiform appendix; (b) Multiplanar reconstructed CT scan shows inflamed epiploic appendage (arrowhead) of the tip portion of a normal vermiform appendix (arrow), with a central linear high attenuation (short arrow). $\mathrm{C}=$ normal cecum; (c) Histopathologic examination shows large fibrofatty tissue (arrowhead) containing tubular structures (short arrows) suspected as engorged vessel and fibrin components, around the tip of the appendix (arrow) (hematoxylin and eosin stain, $\times 10$ ).

epiploic appendagitis of the vermiform appendix (EAA) is rare [1]. Since Hambury [3] reported the first case of primary EAA, similar cases have been reported by Purysko [1], Aslam [2], Sand [4] and Magnuson [5]; the authors diagnosed the patients as having acute appendicitis and immediate appendectomy was performed.

To our knowledge, 5 cases have been previously reported in the English literature, and only one case included radiologic findings [1]. In contrast, our report correlates radiologic and histopathologic findings. The characteristics of the 5 previously reported cases, as well as our own, are summarized in Table 1.

In the literature review, the clinical symptoms of the patients were alike. The presenting symptom of all patients was right lower quadrant pain. Two patients had laboratory results indicative of leukocytosis, and one had mild elevation of C-reactive protein. The size of the inflamed appendage was mentioned for only 
Table 1. Clinical and radiologic features of 6 patients with epiploic appendagitis of the vermiform appendix.

\begin{tabular}{|c|c|c|c|c|c|c|c|c|}
\hline $\begin{array}{l}\text { Literature } \\
\text { source }\end{array}$ & $\begin{array}{c}\text { Age } \\
\text { (years) }\end{array}$ & $\operatorname{Sex}$ & Symptom & Laboratory results & $\begin{array}{l}\text { Size of the } \\
\text { lesion }\end{array}$ & Location of the lesion & CT appearance & Outcomes \\
\hline $\begin{array}{c}1 \\
\text { Hambury [3] }\end{array}$ & 34 & $\mathrm{~F}$ & RLQ pain & Not mentioned & $1.3 \mathrm{~cm}$ & $\begin{array}{l}\text { Junction of the middle } \\
\text { and distal one-third of } \\
\text { the appendix }\end{array}$ & Not applicable & Surgically confirmed \\
\hline $\begin{array}{c}2 \\
\text { Sand [4] }\end{array}$ & 50 & $\mathrm{M}$ & RLQ pain & $\begin{array}{c}\text { Leukocytosis } \\
\text { (WBC } 12 / \mathrm{nL}) \\
\text { Elevated CRP } \\
(1 \mathrm{mg} / \mathrm{dL})\end{array}$ & Not mentioned & Not mentioned & Not applicable & Surgically confirmed \\
\hline $\begin{array}{c}3 \\
\text { Aslam [2] }\end{array}$ & 57 & M & RLQ pain & Leukocytosis & Not mentioned & Near the tip of appendix & Not applicable & Surgically confirmed \\
\hline $\begin{array}{c}4 \\
\text { Magnuson } \\
{[5]}\end{array}$ & 36 & $\mathrm{~F}$ & RLQ pain & Within normal range & Not mentioned & Proximal appendix & Not applicable & Surgically confirmed \\
\hline $\begin{array}{c}5 \\
\text { Purysko [1] }\end{array}$ & 38 & M & RLQ pain & Not mentioned & Not mentioned & Near the tip of appendix & $\begin{array}{l}\text { Periappendiceal fatty oval lesion } \\
\text { with hyperattenuating rim }\end{array}$ & Surgically confirmed \\
\hline Our patient & 32 & M & RLQ pain & $\begin{array}{c}\text { Leukocytosis } \\
\left(\text { WBC } 10,950 / \mathrm{mm}^{3}\right) \\
\text { Elevated ESR } \\
(14 \mathrm{~mm} / \mathrm{h})\end{array}$ & $1.5 \mathrm{~cm}$ & Near the tip of appendix & $\begin{array}{l}\text { Periappendiceal fatty oval lesion with } \\
\text { hyperattenuating rim and central } \\
\text { linear hyperattenuation }\end{array}$ & $\begin{array}{l}\text { Surgically and } \\
\text { pathologically } \\
\text { confirmed }\end{array}$ \\
\hline
\end{tabular}

$\mathrm{F}=$ female; $\mathrm{M}=$ male; $\mathrm{RLQ}=$ right lower quadrant $\mathrm{WBC}=$ white blood cells; $\mathrm{CRP}=\mathrm{C}$-reactive protein; $\mathrm{ESR}=$ erythrocyte sedimentation rate

one patient as $1.3 \mathrm{~cm}$, which is similar to that of our patient, which was measured as $1.5 \mathrm{~cm}$. The location of the lesion was provided in 5 cases, including our case. The most common location of the inflamed appendage was near the tip of the vermiform appendix, in 3 cases. In two cases, the locations of the lesions were the proximal appendix the junction of the middle and distal one-third of the appendix.

The imaging features of acute EA have been well described in CT examinations, that is the most common modality applied for initial diagnosis of acute abdominal pain. The common CT appearance of EA is a fat attenuating pericolic oval lesion with a hyperattenuating rim. A high attenuated central dot, an irregular or a linear focus, may also be present and correspond to thrombosed or engorged central vessels, or central areas of hemorrhage or fibrosis. Wall thickening of the adjacent colon may be present but it is most often normal in thickness [1]. Other findings include localized edema, which is often manifested as streaky fluid attenuation around the appendage that is the source of the image description of "fat stranding", and visibility of the appendage serosa either due to fluid or vascular engorgement [6]. There is little difference in radiologic findings between epiploic appendagitis of the vermiform appendix and that of the colon. The only difference is that lesions of the vermiform appendix are relatively smaller $(1.3$ to $1.5 \mathrm{~cm})$ than those on the serosal surface of the colon (2 to $4 \mathrm{~cm}$ ) [1]. In our case, a $1.5-\mathrm{cm}$ fatty, oval lesion was seen adjacent to the tip portion of the vermiform appendix with a hyperattenuating rim and central linear high attenuation (Figure 1(a), Figure 1(b)).

Representative differential diagnoses of EA are acute appendicitis and acute appendiceal diverticulitis. Unlike acute appendicitis, the appendix is normal in 
caliber, wall enhancement, and thickness, but there can be infiltration of the periappendiceal fat observed on CT due to secondary inflammation [7]. In appendiceal diverticulitis, the typical CT findings include the presence of a round, outpouching lesion beyond the margin of the appendix with prominent enhancement of the diverticulum wall and surrounding fat stranding [1].

EA is generally a self-limited disease, with patients spontaneously recovering within 7 to 30 days. Conservative management with oral anti-inflammatory medication is currently considered the standard management, once an accurate radiological diagnosis has been established [8]. Antibiotics or surgical treatments are rarely warranted and surgical intervention is used only for complications such as inflammation-induced adhesions, secondary abscess, or intestinal occlusions [9] [10]. But in our case, laparoscopic appendectomy was performed by the surgeon, prior to confirmation by $\mathrm{CT}$.

EAA is often misdiagnosed because clinical symptoms are nonspecific and similar to those of other diseases that induce right lower quadrant pain, such as acute appendicitis or diverticulitis, including abdominal pain, nausea, and vomiting. However, if radiologists are familiar with the characteristic radiologic findings of EAA, it is possible to avoid unnecessary surgery, such as negative appendectomy.

We present the first case of EAA in which a typical radiologic image was confirmed by the pathologic findings.

\section{Financial Disclosure}

No funding support or grant was received for this study.

\section{References}

[1] Purysko, A.S., Remer, E.M., Filho, H.M., Bittencourt, L.K., Lima, R.V. and Racy, D.J. (2011) Beyond Appendicitis: Common and Uncommon Gastrointestinal Causes of Right Lower Quadrant Abdominal Pain at Multidetector CT. Radiographics, 31, 927-947. https://doi.org/10.1148/rg.314105065

[2] Aslam, M.B. and Hasan, N. (2009) Torsion of an Appendix Epiploica Present at the Vermiform Appendix: A Rare Cause of Acute Abdomen. Turkish Journal of Trauma and Emergency Surgery (Ulusal Travma Dergisi), 15, 509-510.

[3] Hambury, H.J. (1952) Torsion of an Appendix Epiploica of the Vermiform Appendix. British Journal of Surgery, 40, 176-177. https://doi.org/10.1002/bjs.18004016019

[4] Sand, M., Bonhag, G., Bechara, F.G., Sand, D. and Mann, B. (2009) An Inflamed Necrotic Appendix Epiploicum with Immediate Contact to a Non-Inflamed Appendix Vermiformis: A Case Report. Journal of Medical Case Reports, 3, 57. https://doi.org/10.1186/1752-1947-3-57

[5] Magnuson, A., Reber, H., Reyna, P., Ries, D. and Aanning, H.L. (2006) Infarcted Epiploic Appendage of the Vermiform Appendix Masquerading as Acute Appendicitis. The Journal of the South Dakota State Medical Association, 59, 511-513.

[6] Eberhardt, S.C., Strickland, C.D. and Epstein, K.N. (2016) Radiology of Epiploic Appendages: Acute Appendagitis, Post-Infarcted Appendages, and Imaging Natural 
History. Abdominal Radiology (New York), 41, 1653-1665.

https://doi.org/10.1007/s00261-016-0757-0

[7] Nadida, D., Amal, A., Ines, M., Makram, M., Amira, M., Leila, B.F. and Lotfi, H. (2016) Acute Epiploic Appendagitis: Radiologic and Clinical Features of 12 Patients. International Journal of Surgery Case Reports, 28, 219-222.

https://doi.org/10.1016/j.ijscr.2016.09.015

[8] Almuhanna, A.F., Alghamdi, Z.M. and Alshammari, E. (2016) Acute Epiploic Appendagitis: A Rare Cause of Acute Abdomen and a Diagnostic Dilemma. Journal of Family and Community Medicine, 23, 48-50. https://doi.org/10.4103/2230-8229.172234

[9] Sand, M., Gelos, M., Bechara, F.G., Sand, D., Wiese, T.H., Steinstraesser, L. and Mann, B. (2007) Epiploic Appendagitis-Clinical Characteristics of an Uncommon Surgical Diagnosis. BMC Surgery, 7, 11. https://doi.org/10.1186/1471-2482-7-11

[10] Singh, A.K., Gervais, D.A., Hahn, P.F., Sagar, P., Mueller, P.R. and Novelline, R.A. (2005) Acute Epiploic Appendagitis and Its Mimics. Radiographics, 25, 1521-1534. https://doi.org/10.1148/rg.256055030

\section{Abbreviations}

APCT abdominopelvic computed tomography

CT computed tomography

EA epiploic appendagitis

EAA epiploic appendagitis of the vermiform appendix

WBC white blood cells

CRP C-reactive protein

ESR erythrocyte sedimentation rate

RLQ right lower quadrant 